\title{
Aggregation of the littorinid snail Littorina unifasciata in New South Wales, Australia
}

\author{
M. G. Chapman* \\ Institute of Marine Ecology, Marine Ecology Laboratories, University of Sydney, New South Wales 2006, Australia
}

\begin{abstract}
Littorina unifasciata is a small littorinid snail found at mid- to high-shore levels on rocky shores in Australia. Much has been published on patterns of distribution and abundance of $L$. unifasciata on different shores, at different heights on the shore and in different microhabitats, but there is little information on patterns of aggregation of this species. Nevertheless, this species tends to form very distinct clusters when emersed during low tide. This study is a quantification of aggregation by L. unifasciata on different shores, levels on the shore and in different microhabitats. The use of patches of habitat of different size during low tide and high tide is also examined. Aggregation was variable from time to time and place to place and individual snails did not show a consistent tendency to aggregate on different occasions. Snails were less aggregated when they spread out to feed during high tide than when emersed during low tide, but this was only found at very small spatial scales because snails do not move far to feed. Therefore, the cues that operate to cause the snails to aggregate in some patches and not others appear to be operating at the scale of centimetres, rather than metres. This suggests that many of the traditional explanations for patterns of aggregation in intertidal animals, such as those having to do with desiccation or temperature, may not be important in this species. This phenomenon may be more widespread among intertidal animals than is currently recognised, but it will be necessary to examine patterns and test models about ecological processes at small spatial scales within shores, in addition to among shores, before this can be determined.
\end{abstract}

KEY WORDS: Aggregation - Intertidal $\cdot$ Littorinid $\cdot$ Spatial pattern

\section{INTRODUCTION}

Many habitats are extremely patchy in space and time (Den Boer 1968, Connell 1975, Menge \& Sutherland 1976, Wiens 1976, Sousa 1984, Underwood \& Denley 1984). Spatial differences and/or temporal changes in patchiness may be due to physical features or to biological variables, such as competition and predation, which may themselves alter as assemblages of species in habitats change. Two broad-scale environmental gradients affect intertidal assemblages: the upshore increase in the period of emersion during low tide and an alongshore gradient of wave exposure. There are also, however, small-scale differences in topography, aspect, habitat complexity and diversity,

•E-mail: gee@bio.usyd.edu.au which interact to cause small-scale patchiness and different microhabitats within areas of only a few square metres.

Animals and plants show a range of patterns of dispersion from regularly spaced to strongly aggregated. Patterns of dispersion are dependent on the spatial scale at which the populations are examined (GreigSmith 1952, Pielou 1969), but all populations are aggregated at some spatial scale(s). Patchiness is a feature of many intertidal shores (Southward 1953, Paine \& Levin 1981) and many intertidal species show smallscale, within-habitat patterns of aggregation. Such organisms include macro- (Underwood \& Jernakoff 1984) and microalgae (Hill \& Hawkins 1991), barnacles (Denley \& Underwood 1979), limpets (Mackay \& Underwood 1977), grazing snails (Underwood 1976a, b, Garrity \& Levings 1984) and predatory whelks (Feare 1971, Moran 1985). 
Dispersion of sessile species is largely determined by patterns of recruitment (De Wolf 1973, Hawkins \& Hartnoll 1982) and/or mortality (Dayton 1971, Denley \& Underwood 1979, Keaugh \& Downes 1982). In mobile animals, which can move and select some habitats over others, patterns of dispersion can be altered by the behaviour of the animals on an irregular or regular basis (Mackay \& Underwood 1977, Chelazzi et al. 1988. Turchin 1988. Underwood \& Chapman 1989, 1992) Aggregating animals may move towards or away from each other (Rhode \& Sandland 1975) or particular microhabitats (Levings \& Garrity 1983, Chapman \& Underwood 1994). Wide-ranging invertebrates, such as flying insects, may locate certain habitats using visual or olfactory cues (Stanton 1983). Although vision may be less important in marine snails, some species also show directed visual responses to certain features of the environment (Evans 1961, Hamilton 1978, Chelazzi \& Vannini 1980). Many species of molluscs, however, show directed movement in response to airor waterborne odours (Rhode \& Sandland 1975. Chelazzi et al. 1988) or trails deposited on the substratum (Cook 1971, Cook \& Cook 1975, Chelazzi et al. 1985). Aggregating individuals do not necessarily follow their own trails to move into an aggregation, but may respond to the trails of conspecifics.

Instead of directed responses to certain stimuli, mobile animals may aggregate because of changes in undirected movement, e.g. decreasing rates of locomotion or increasing circling in areas with large densities of conspecifics (Turchin 1987). Nerita versicolor and $N$. textilis increase kinesis in the dark, thus accumulating in crevices (Bovjberg 1984). Crevices influence rates of dispersal of the predatory whelk Morula marginalba, causing aggregations in certain microhabitats (Fairweather 1988). Underwood \& Chapman (1989) have, however, shown that changes in rates of dispersal in response to topographic complexity do not necessarily lead to aggregations of Littorina unifasciata in. different habitats. Aggregations in some species are obviously associated with certain features of habitat (Underwood 1976a, b, Garrity \& Levings 1984, Moran. 1985, Chapman 1994a). Other species form aggregations that cannot easily be associated with features of the environment (Jenner 1959).

Littorina unifasciata are small littorinids (mean shell length generally less than $1 \mathrm{~cm}$ ) found between mid-and high-shore levels on most intertidal shores in New South Wales, Australia. Their mean density and size vary from shore to shore, from height to height and among different microhabitats within a particular shore level (Underwood 1981a, Underwood \& Chapman 1989, 1992. Chapman 1994b, 1995). When emersed, L. unifasciata show consistent associations with certain patches of habitat between 20 and $2500 \mathrm{~cm}^{2}$ (i.e. $0.25 \mathrm{~m}^{2}$ ) in size, causing small-scale differences in density from one patch of habitat to another (Underwood \& Chapman 1992). In addition to differences in densities among patches of habitat, $L$. unifasciata frequently aggregate into clusters in which the snails are in contact with one another. These clusters (or aggregations) may consist of only a few or many hundreds of individuals, and are found during low tide on emersed rock surfaces, on barnacle shells and around the edges of shallow pools. They may persist for many days. L. unifasciata therefore show 2 types of small-scale variation of dispersion: differences in densities from one patch of habitat to another, and variation in aggregation of individuals into clusters within and among patches of different densities. Despite these obvious patterns, there are no published data on variability in patterns of aggregation (i.e. clustering) of $L$. unifasciata in different habitats

Aggregation into clusters by intertidal animals may reduce stress attributable to high or low temperatures (Feare 1971, Marchetti \& Geller 1987) or desiccation (Levings \& Garrity 1983, Lively \& Raimondi 1987) during emersion or predation by fish during high tide (Levings \& Garrity 1983). Littorina unifasciata, which live at high levels on the shore, are exposed to prolonged periods of emersion and, towards the upper end of their range, snails can be continuously emersed for many days in hot weather (pers. obs.). If aggregation reduces stress associated with prolonged emersion, one can predict that $L$. unifasciata should be more aggregated higher than lower on the shore. Similarly, L. unifasciata should be more aggregated on broad horizontal surfaces which are exposed to the full strength of the sun than on vertical surfaces where physical stresses associated with emersion are less extreme (Garrity 1984).

Because many small aggregations of Littorina unifasciata are associated with topographic features of the substratum, such as pits and crevices, clustering may be correlated with the topographic complexity of the habitat. Large aggregations are, however, not always associated with visible topographic features, which suggests that snails may aggregate in response to conspecifics, rather than in response to particular features of the habitat. L. unifasciata follow conspecific trails, although not all individuals follow trails at any one time (Chapman 1992) Unquantified observations show that trail-following frequently leads to aggregation. If aggregation results from trail-following, aggregation should increase with increasing density of conspecifics because of the greater probability of a snail encountering a trail and the likelihood that a greater number of snails will encounter each trail.

Any intraspecific effect of density will obviously increase if the mean density increases, but it may also be affected by aggregation. For example, if animals move small distances so that individuals only interact with 
close neighbours, aggregation in the population will increase the effects of density on those individuals in aggregations more than on solitary individuals (Fig. 1a, b). Increased aggregation will intensify any effects of density on the population as a whole. The extent to which this occurs will depend on the degree of aggregation and the spatial scale over which individuals interact. During low tide, mean densities and patterns of aggregation in Littorina unifasciata differ among patches from 20 to $2500 \mathrm{~cm}^{2}$ (Underwood \& Chapman 1992, Chapman 1994b). It does not, however, follow that similar patterns occur during high tide.

Many models explaining clustering of individuals during low tide incorporate responses to environmental conditions during emersion, e.g. stress due to desiccation or temperature. Aggregation when emersed, however, is not necessarily a behavioural response to these environmental conditions. If certain patches of habitat are preferred when feeding during high tide and animals remain in these patches when the tide drops, patterns of dispersion during low tide will reflect patterns of habitat use during high tide. Any causes of or apparent advantages from aggregation will refer to conditions when the animals are active and submersed and not while they are inactive and emersed. Therefore, any models proposed to explain these patterns should consider responses to conditions during high tide. Alternatively, Littorina unifasciata
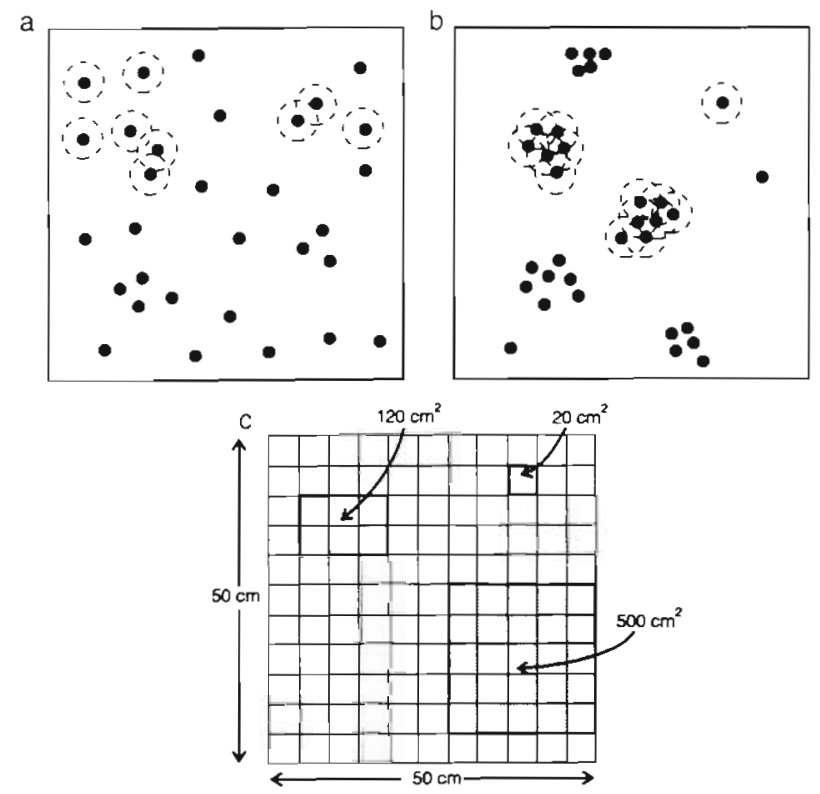

Fig. 1. Littorina unifasciata. (a) Animals come into contact with fewer other individuals when they are randomly dispersed than (b) when they are aggregated if they do not move large distances and have a small foraging range (dashed line); (c) division of a $0.25 \mathrm{~m}^{2}$ quadrat into 20,120 and $500 \mathrm{~cm}^{2}$ subquadrats for measurements of density, aggregation and mean crowding of snails during low and high tide may disperse widely while feeding and only aggregate during low tide, as do many other intertidal grazers (Chelazzi et al. 1988). In this case, causes of or advantages from aggregation will be associated with emersion, and any models explaining aggregation should be concerned with conditions prevailing during low tide. To distinguish among these different models, dispersion should be examined during low tide and high tide to determine whether snails remain in the same patches or use different parts of the habitat during each state of the tide. Patterns should be identified at a range of spatial scales within the normal foraging range of this species so that hypotheses about the processes influencing aggregation can be identified and tested at the appropriate spatial scales.

\section{MATERIALS AND METHODS}

Study sites. Most data were collected in the Cape Banks Scientific Marine Research Area (Cape Banks) on the northern headland of Botany Bay, New South Wales, Australia. General patterns of distribution of Littorina unifasciata on these shores are described in Chapman (1994a, b). Aggregation with respect to slope of the shore was examined at Clovelly and Coogee, 2 shores within the Sydney metropolitan district (Clovelly = Shore 1 in Chapman 1995). Unlike the shores at Cape Banks, which are relatively flat, extensive rock platforms, these 2 shores are narrow with large boulders (some of which exceeded $2 \mathrm{~m}$ in height) within the distribution of $L$. unifasciata. These boulders had large areas of vertical and horizontal surfaces. $L$. unifasciata were found on the sides and tops of the boulders and on the rock platform adjacent to them. Equivalent vertical and horizontal surfaces are not found within the distribution of L. unifasciata at Cape Banks, except high on the shore where the vertical surfaces are at the upper limit of this species. The vertical surfaces described in Chapman (1994b) were not extensive (hence the use of $20 \mathrm{~cm}^{2}$ quadrats for estimates of densities in Chapman 1994b) and were therefore not appropriate for a study of patterns of dispersion.

Aggregation was calculated as Pielou's $\alpha$ (1959), which is a measure of distances to nearest neighbours from random points within an area. Pielou's $\alpha$ gives an estimation of aggregation without potential influence of the size of quadrat used to sample the area (Pielou 1969). Each quadrat was photographed and the photographs projected onto a grid. Distance to the nearest Littorina unifasciata was measured from each of 20 random points on each photograph. The topographic complexity of the rock surface was estimated using the method of Underwood \& Chapman (1989). This gives a topographic index between 0 and 1 , which 
increases with increasing topographic complexity of the substratum.

The relationships between aggregation (Pielou's $\alpha$ ) and other environmental variables were examined using Pearson's product-moment correlation coefficient. Differences among mean values of $\alpha$ for other variables) were identified from analyses of variance, after transformation of the data if variances were heterogeneous (determined from Cochran's test). Appropriate means were then compared using SNK tests (Winer 1971, Underwood 1981b)

Broad-scale patterns of aggregation. To test the hypotheses that Littorina unifasciata were more aggregated higher than lower on the shore, in areas with greater densities of snails and in areas with increased topographic complexity, Pielou's $\alpha$ was measured in replicate quadrats at 2 levels on each of 2 shores (Shores 2 and 3 at Cape Banks; Chapman 1994a). To test the hypothesis that the degree of aggregation is determined by intrinsic physical features of the habitat, aggregation in the same areas was compared on replicate occasions. Twenty-five $400 \mathrm{~cm}^{2}$ quadrats were randomly selected along $50 \mathrm{~m}$ horizontal transects towards the upper limit (high shore) and towards the lower limit of the distribution of L. unifasciata (midshore) on each shore. Each quadrat was photographed during 2 periods of low tide, separated by approximately a month, although heights on each shore were not necessarily sampled on the same days. A month is adequate time for the population in an area this size (400 $\mathrm{cm}^{2}$ ) to change (Underwood \& Chapman 1989). Pielou's $\alpha$ was calculated from each photograph and the topographic complexity was measured in each quadrat. $\alpha$ was then correlated with the density of the snails and the topographic complexity of the substratum at each time of sampling and compared separately between the 2 times of sampling for each level on each shore.

To determine whether the average degree of aggregation of Littorina unifasciata was greater at higher rather than at lower points on the shore, $\alpha$ was andlysed from high shore and midshore levels on each shore at both times of sampling. Because the same quadrats were sampled each time (in order to test the hypothesis about consistency of aggregation in the same sites), data from 12 randomly selected quadrats were used for each time of sampling in this analysis. Height on the shore was treated as a fixed factor, shores as a random factor, and times of sampling were nested in the Shore $\times$ Height interaction.

Small-scale patterns of aggregation. Aggregation on surfaces with different slopes: To test the hypothesis that aggregation is greater on horizontal than on vertical surfaces, aggregation was measured at 6 sites on the tops and sides of boulders and on the adjacent rock platform at Clovelly and Coogee. At Clovelly, densities of snails per $2500 \mathrm{~cm}^{2}$ and Pielou's $\alpha$ in $400 \mathrm{~cm}^{2}$ areas were calculated from 4 random quadrats of each size at 3 vertical sites (the sides of boulders) and at 3 horizontal sites (the tops of 2 boulders and at 1 site on the adjacent rock platform). Horizontal and vertical surfaces were not necessarily measured on the same boulders, so sites were nested within the factor of slope in the analyses. The shell lengths of 20 aggregated and 20 solitary snails at each site were measured because solitary snails appeared to be larger than aggregated snails. Snails were randomly chosen by placing quadrats on the rock surface and collecting the solitary and aggregated snails nearest marked points on the quadrat. All snails from each aggregation were mixed together, and 5 snails were chosen randomly from each aggregation (if there were 5 or more available, otherwise all snails in that aggregation were measured). This was continued until the requisite number of snails was measured. Similar data were collected from Coogee, but only 2 vertical and 2 horizontal surfaces were sampled with 3 quadrats on each surface, and the shell lengths of 19 snails were measured.

Experimental analysis of aggregation on surfaces with different slopes: Many different models may explain greater aggregation on horizontal than on vertical surfaces (see 'Results') and these can only be distinguished by experimental manipulations. First, aggregation may be determined by the slope of the rock. If this were correct, snails placed on horizontal surfaces should aggregate more than those placed on vertical surfaces, irrespective of their origin. Second, certain individuals may have more intrinsic tendency to aggregate than others, and these types may be more common on horizontal than on vertical surfaces. In this case, snails obtained from aggregations (i.e. clusters of individuals in contact with one another) should be more inclined to aggregate than solitary snails, irrespective of their treatment or the slope of the surface on which they are placed. A third model is that the tendency to aggregate may be induced by variables associated with the slope on which the snails have been living. If this model were correct, snails obtained from horizontal surfaces should aggregate more than those obtained from vertical surfaces, irrespective of whether they are collected from an aggregation or not, and irrespective of the slope of the surface on which they are placed.

These alternatives were tested experimentally at Clovelly. Solitary and aggregated snails from vertical or horizontal surfaces were subjected to one of 9 different treatments (summarised in Table 1). Solitary snails were defined as those not in contact with any other snails at the start of the experiment. Aggregated snails were collected from clusters of at least 5 individuals. Undisturbed snails were marked in situ with a dot of nontoxic enamel paint (Chapman 1986) 
Table 1. Littorina unifasciata. Experimental treatments to determine whether increased aggregation on horizontal surfaces was due to slope or characteristics of the snails normally found in each habitat. Sol.. originally solitary snails; Agg.. originally aggre-

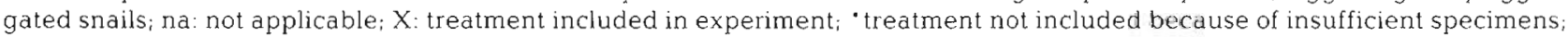
- treatment not included because snails would not grip the substratum (details ın text)

\begin{tabular}{|c|c|c|c|c|c|}
\hline \multirow[t]{2}{*}{ Treatment } & \multirow{2}{*}{$\begin{array}{l}\text { Slope of rock surface: } \\
\text { Original dispersion of snails: }\end{array}$} & \multicolumn{2}{|c|}{ Vertical } & \multicolumn{2}{|c|}{ Horizontal } \\
\hline & & Sol. & Agg. & Sol. & Agg \\
\hline 1 Undisturbed & & $x$ & $\cdot$ & $X$ & $x$ \\
\hline 2 Disturbed & & $\cdots$ & . & $x$ & $x$ \\
\hline 3 Translocated to new position & & $x$ & . & $x$ & $x$ \\
\hline 4 Transplanted sol to agg., same slope & & $x$ & na & $x$ & na \\
\hline 5 Transplanted agg to sol., same slope & & na & $\cdot$ & na & $\mathrm{X}$ \\
\hline 6 Transplanted sol. to sol, different slope & & $\mathrm{X}$ & na & $\mathrm{x}$ & na \\
\hline 7 Transplanted sol. to agg., different slope & & $x$ & na & $\mathrm{x}$ & na \\
\hline 8 Transplanted agg. to sol., different slope & & na & $\cdot$ & na & $x$ \\
\hline 9 Transplanted agg. to agg., different slope & & na & $\cdot$ & na & $\mathrm{x}$ \\
\hline
\end{tabular}

(Treatment 1 in Table 1). All other snails were handled, marked with paint and replaced on the substratum. To obtain the experimental groups of snails necessary to test these hypotheses, snails were transplanted between habitats (horizontal to vertical surfaces and vice versa) and between patterns of dispersion (solitary to aggregated and vice versa). Therefore, transplanted snails were moved into a different pattern of dispersion [i.e. solitary to aggregated (Treatment 4) or vice versa (Treatment 5)] on surfaces of the same slope, or to the same (Treatments 6 and 9) or a different pattern of dispersion (Treatments 7 and 8) on surfaces of a different slope (Table 1). These treatments are all necessary to examine the effects of slope, history of the snails and original pattern of dispersion on the tendency to aggregate. Control treatments included disturbed snails which were replaced in the same position (Treatment 2) and translocated snails which were moved to a new position, but placed in the same configuration on rocks of the same slope (Treatment 3) (see Chapman 1986, Underwood 1988, Chapman \& Underwood 1992 for descriptions of the need for experimental controls). Unfortunately, it was not possible to incorporate the full set of experimental treatments. There were not enough aggregated snails on vertical surfaces to be included in all treatments; therefore, treatments involving these snails were omitted. It was also not possible to include disturbed snails on vertical surfaces because they would not reattach after dislodgment. All other snails moved onto vertical surfaces were placed in very small pits in the rock surface, but this could not be done to disturbed snails because they must (by definition) be replaced in their original position which was not necessarily in a pit (Chapman 1986)

To examine these models, 10 snails in each treatment were placed on each of 6 horizontal and 6 vertical surfaces. One day later, the snails of each treat- ment in aggregations (i.e. in contact with another snail in a cluster of 5 or more snails) were counted. Because solitary and aggregated snails from vertical and horizontal surfaces were not subjected to all treatments, the data could not be examined in 1 analysis. Solitary and aggregated snails from horizontal surfaces, subjected to 1 of 6 different treatments, were compared to examine the effects of disturbance, translocation, slope and the original pattern of dispersion (solitary or aggregated) on subsequent aggregation. The second analysis compared solitary snails from vertical and horizontal surfaces, subjected to 1 of 5 different treatments, to examine the effects of translocation, the origin of the snails, dispersion and slope on the tendency to aggregate. This experiment examined aggregation of snails from different origins in different habitats after 1 period of activity. Longer time was not provided because the history of the individuals was altered by the experimental treatments and would no longer be appropriate after 1 period of activity. This assumes that environmental conditions during the short experimental period were adequate to induce aggregation in different habitats, but does not address questions about the survival value of this behaviour

Dispersion during low or high tide. Dispersion during low or high tide was measured at 2 replicate sites on Shore 1 at Cape Banks. At each site, four $2500 \mathrm{~cm}^{2}$ quadrats were photographed during a low tide, and again during the next high tide when the sites were awash. During low tide, all of the snails were inactive; during the high tide, most were active. The dispersion of Littorina unifasciata was examined at the spatial scales of $2500,500,120$ and $20 \mathrm{~cm}^{2}$ at each state of the tide (Fig. 1c).

At each spatial scale, 3 measures of dispersion were estimated. First, the mean density per unit area was estimated. Second, the variance:mean ratio among repli- 
cate quadrats of each size was calculated to give a measure of the amount of variability in density among patches of habitat (i.e. among quadrats) of that particular size. This ratio is generally considered to be densityindependent (Pielou 1969), although this may not strictly be so (Underwood pers. comm.). Third, Lloyd's index of mean crowding (Lloyd 1967) was estimated for patches (i.e. quadrats) of each size. This index is a measure of the average amount of crowding experienced by all individuals in the population and incorporates measures of density and aggregation among individuals.

There were four $2500 \mathrm{~cm}^{2}$ quadrats per site. Therefore, at the largest spatial scale there were 4 replicate measures of density per site ( 1 per quadrat), but each site gave 1 reading for aggregation and mean crowding (estimated from all 4 quadrats). Each quadrat was then divided into 121 small subquadrats, each approximately $20 \mathrm{~cm}^{2}$ in size. Densities from subsets of these were then combined to provide data from patches of different sizes (Fig. 1C).

Twenty-five adjacent $20 \mathrm{~cm}^{2}$ subquadrats were combined to give areas of $500 \mathrm{~cm}^{2}$ There were 4 of these areas per $2500 \mathrm{~cm}^{2}$ quadrat. Two areas were randomly selected during each low and high tide to provide 2 measures of density. The variance:mean ratio and Lloyd's index were calculated from two random pairs of these areas per $2500 \mathrm{~cm}^{2}$ quadrat during low and high tide, thus giving 2 replicate values per quadrat for each state of the tide

Similarly, 6 adjacent $20 \mathrm{~cm}^{2}$ subquadrats were combined to form areas of $120 \mathrm{~cm}^{2}$ (Fig. 1c). There were 15 of these smaller quadrats per $2500 \mathrm{~cm}^{2}$. Mean density was not examined at this scale nor at the smaller spatial scale. Within each $2500 \mathrm{~cm}^{2}$ area, Lloyd's index and the variance:mean ratio were calculated for 2 sets of data, each of 5 randomly selected $120 \mathrm{~cm}^{2}$ quadrats, during each low and high tide. These calculations provide 2 independent measures of aggregation and crowding per quadrat for each state of the tide.

The variance:mean ratio and mean crowding were estimated for $20 \mathrm{~cm}^{2}$ subquadrats within $500 \mathrm{~cm}^{2}$ areas because of the large number of subquadrats of this size with counts of zero in $2500 \mathrm{~cm}^{2}$. For each state of the tide, comparisons were made within 2 randomly selected $500 \mathrm{~cm}^{2}$ areas

The densities of snails in each quadrat (of appropriate size) were ranked and the data from low and high tides compared using Spearman's rank correlation coefficient. At the spatial scale of $500 \mathrm{~cm}^{2}$, the data from the four $2500 \mathrm{~cm}^{2}$ quadrats were combined to provide an adequate sample for analysis. At the smaller spatial scales, each $2500 \mathrm{~cm}^{2}$ area was analysed separately. The data for $20 \mathrm{~cm}^{2}$ subquadrats were compared using the raw data instead of ranks because there were many zero values and, therefore, tied ranks.
Because data on densities, variance:mean ratio and Lloyd's index of mean crowding were obtained from independent subquadrats within each quadrat during low and high tide. comparisons between the 2 sites and the different states of the tide were investigated using analyses of variance. The state of the tide was treated as a fixed factor, sites as a random factor and quadrats were nested within sites.

\section{RESULTS}

\section{Broad-scale patterns of aggregation}

Littorina unifasciata were significantly aggregated $(p<0.05)$ in $80 \%$ and $46 \%$ of quadrats in the high and midshore levels of Shore 2 (the more exposed shore) and $62 \%$ and $86 \%$ of quadrats in the high and midshore levels of Shore 3 (the more sheltered shore), respectively (averaged over both times of sampling). The proportion of quadrats in which Pielou's $\alpha$ was significant $(p<0.05)$ was an estimate of the proportion of each area in which the snails were distributed in a non random, aggregated pattern. This did not vary from time to time at the 2 heights on Shore 3, nor at high shore levels on Shore $2\left(\chi^{2}=0.76,0.17\right.$ and 0.00 , respectively, each with $1 \mathrm{df}, \mathrm{p}>0.05)$. At the midshore level on Shore 2, snails were significantly aggregated in fewer quadrats during the second than during the first time of sampling $\left(\chi^{2}=9.74,1 \mathrm{df}, \mathrm{p}<0.001\right)$.

Aggregation was not usually correlated with density of snails, but increased with increasing density high on Shore 3 during Time 1 and at the midshore level of Shore 3 during Time 2 (Table 2). Aggregation was also not generally correlated with topographic complexity of the rock surface, except for decreased aggregation with increasing complexity at the midshore level of Shore 2

Table 2. Littorina unifasciata. Correlation coefficient $\left(\mathrm{r}_{\mathrm{S}}\right)$ for Pielou's $\alpha$ and density of snails, topographic complexity of the rock and different times of sampling at 2 levels on each of 2 shores (Shores 2 and 3$)(n=25)$. In this and subsequent tables, ns: $p>0.05 ; \cdot p<0.05 ; \cdots p<0.01 ; \cdots p<0.001$

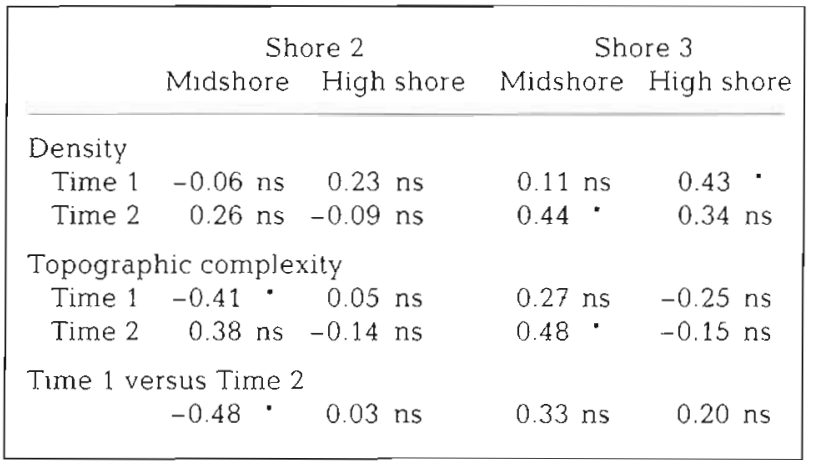


during the first time of sampling and the reverse pattern on Shore 3 during the second time of sampling (Table 2). A subset of these data from Shore 3 is presented in Fig. 2. Aggregation varied from quadrat to quadrat but was not consistently correlated with either the density of the snails nor the topographic complexity of the rock. Except for a negative correlation between the first and second time of sampling at midshore levels on Shore 3 (when there was also a significant decrease in the amount of aggregation), there were no significant correlations between the 2 times of sampling (Table 2).

Analysis of variance compared the average degree of aggregation across shores and times of sampling without considering whether the snails were significantly aggregated or not (shown by nearest neighbour analysis). This analysis showed that although in general the degree of aggregation did not vary from time to time, there was significantly less aggregation during the second time of sampling in midshore sites on Shore 2 [Times (Shores $\times$ Heights), $F=2.77,4$ and $88 \mathrm{df}, \mathrm{p}<0.05 ;$ Cochran's test, $C=0.24, p>0.05]$. Over and above this, however, Littorina unifasciata were significantly more aggregated at high shore levels compared to midshore levels on Shore 2, but the opposite trend was found on Shore 3 $(F=9.60,1$ and $4 \mathrm{df}, \mathrm{p}<0.05)$. The means showed significant aggregation at each level on each shore (Shore 2 midshore mean $=1.78, \mathrm{SE}=0.20$; high shore mean $=2.84, \mathrm{SE}=0.31$; Shore 3 midshore mean $=3.50$, $\mathrm{SE}=0.47$; high shore mean $=1.82, \mathrm{SE}=0.26$ ) .

\section{Small-scale patterns of aggregation}

Patterns of aggregation on surfaces of different slope

There were no significant differences between densities on vertical and horizontal surfaces at either Clovelly or Coogee, although there were fewer snails on vertical surfaces (mean $=20.6, \mathrm{SE}=5.5$ ) than horizontal surfaces $($ mean $=38.3, \mathrm{SE}=5.1)$ at Clovelly. At Coogee, the reverse trend was found (vertical surfaces: mean $=69.5$, $\mathrm{SE}=22.3$; horizontal surfaces: mean $=36.7, \mathrm{SE}=7.8$ ).

On each shore, Littorina unifasciata were more aggregated on horizontal than vertical surfaces, irrespective of density of snails. At Clovelly, there was a significant degree of aggregation in 11 of the 12 quadrats examined on horizontal surfaces, but in only 1 of the 12 quadrats on vertical surfaces $\chi^{2}=16.67$, $1 \mathrm{df}, \mathrm{p}<0.001$ ). Similarly, at Coogee, there was signifi- cant aggregation in 5 of the 6 horizontal sites, but only 1 of the 6 vertical sites $\left(\chi^{2}=5.33,1 \mathrm{df}, \mathrm{p}<0.05\right)$.

At Clovelly and Coogee, there were significant differences in mean size from site to site $(F=50.37,4$ and $228 \mathrm{df}, \mathrm{p}<0.001 ; F=22.46,2$ and $144 \mathrm{df}, \mathrm{p}<0.001$, respectively). At Clovelly, snails in aggregations were significantly smaller than solitary snails $(F=9.25,1$ and $4 \mathrm{df}, \mathrm{p}<0,05$; Fig. 3a), but at Coogee, aggregated and solitary snails were of similar sizes (Fig. 3b).

\section{Experimental analysis of aggregation on surfaces} of different slope

All snails from the experimental treatments were recovered, so neither disturbance, dispersion at the start of the experiment (i.e. solitary or aggregated) nor slope affected survival during $24 \mathrm{~h}$. The first analysis examined aggregation by snails which were originally solitary or aggregated on horizontal surfaces placed back onto horizontal surfaces or placed on vertical surfaces to examine whether the past behaviour of the snails (i.e. whether they were obtained from aggregations or not) influenced their tendency to aggregate. Similar numbers of snails were found in aggregations, irrespective of whether they were originally obtained from aggregations or were solitary $(F=0.11,1$ and $60 \mathrm{df}, \mathrm{p}>0.05$, Cochran's test $C=0.18, \mathrm{p}>0.05$ ). Differences among means giving rise to the significant 

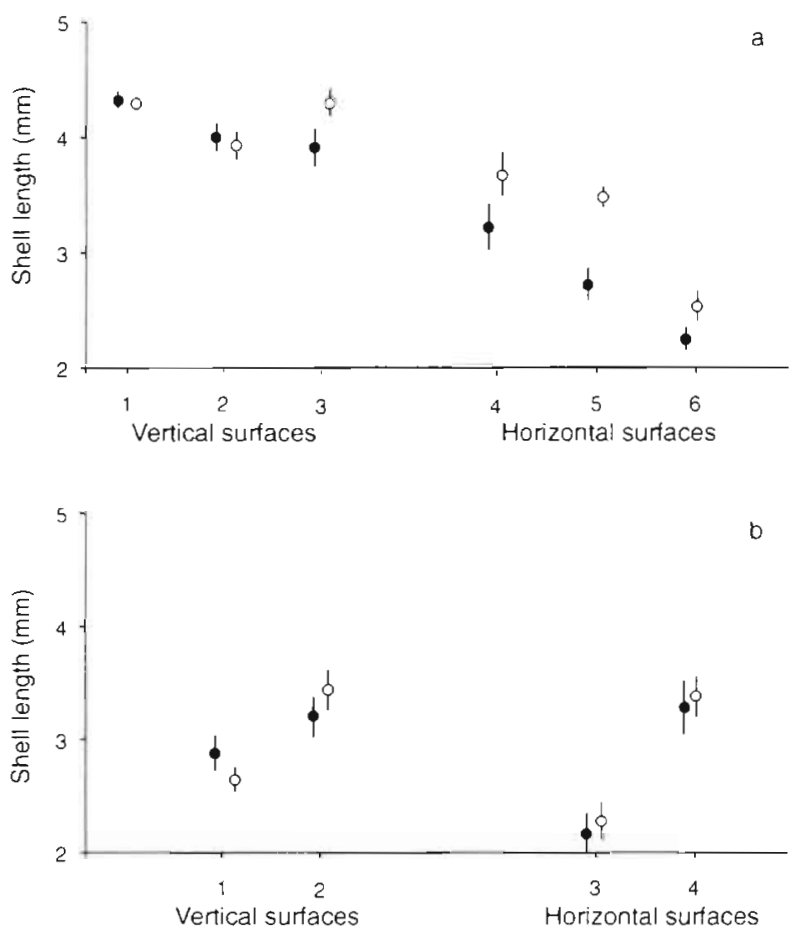

Fig. 3. Littorina unifasciata. Mean shell length (SE) of solitary $(0)$ and aggregated $(\bullet)$ snails on vertical and horizontal rock surfaces at (a) Clovelly and (b) Coogee; $\mathrm{n}=20$ and 19 , respectively

effect of Treatment $(F=3.56,5$ and $60 \mathrm{df}, \mathrm{p}<0.05)$ could not be identified using SNK tests. In general, however, fewer snails aggregated on vertical surfaces (Treatments 6 to 9 in Table 1 and Fig. 4a) than on horizontal surfaces, irrespective of treatment (Fig. 4a).

Solitary snails which were originally obtained from vertical or horizontal rock surfaces were then compared to test whether their past history with respect to the aspect of the surface on which they had been living influenced their tendency to aggregate. The numbers of snails found in aggregations varied according to treatment and origin $(F=2.79,4$ and $50 \mathrm{df}, \mathrm{p}>0.05$, Cochran's test $C=0.24, p>0.05$ ). Snails from horizontal rock-surfaces were less aggregated when transplanted to vertical surfaces than when left on horizontal surfaces (compare differences between Treatments 6 and 7 with treatments 1,3 and 4 for snails from horizontal surfaces; Fig. 4 b). Snails from vertical surfaces, however, showed little aggregation, irrespective of the treatment (compare similarities between Treatment 7 (placed onto horizontal surfaces) and all other treatments (replaced onto vertical surfaces); Fig. 4b]. Therefore, snails moved from vertical to horizontal surfaces showed less tendency to aggregate than the snails found naturally on horizontal surfaces. They behaved similarly to those remaining on vertical surfaces. Being placed as solitary individuals or being placed in an aggregation did not influence the probability of being found in an aggregation $1 \mathrm{~d}$ later in either set of snails on either slope.

\section{Dispersion during low or high tide}

Statistical comparisons in measures of mean density, mean ratio of variance:mean or mean levels of crowding were not made at the scale of $0.25 \mathrm{~m}^{2}$. The data, however, indicated few changes in any measure of dispersion or aggregation between low and high tide at either site [mean density (SE): Site 1, low tide, $472.3(47.9)$; high tide, 448.0 (61.5); Site 2, low tide, 1154.5 (80.5); high tide, 918.8 (67.3); variance:mean: Site 1, low tide, 19.4; high tide, 33.7; Site 2, low tide, 22.5; high tide, 19.7; Lloyd's index of mean crowding: Site 1, low tide, 485.5 ; high tide, 472.3; Site 2, low tide, 1170.4; high tide, 932.5].

At smaller spatial scales, there was generally no correlation between the densities of Littorina unifasciata in subquadrats of 500,120 or $20 \mathrm{~cm}^{2}$ during low tide compared to during high tide within either site. The only exceptions were at the spatial scale of $120 \mathrm{~cm}^{2}$ in

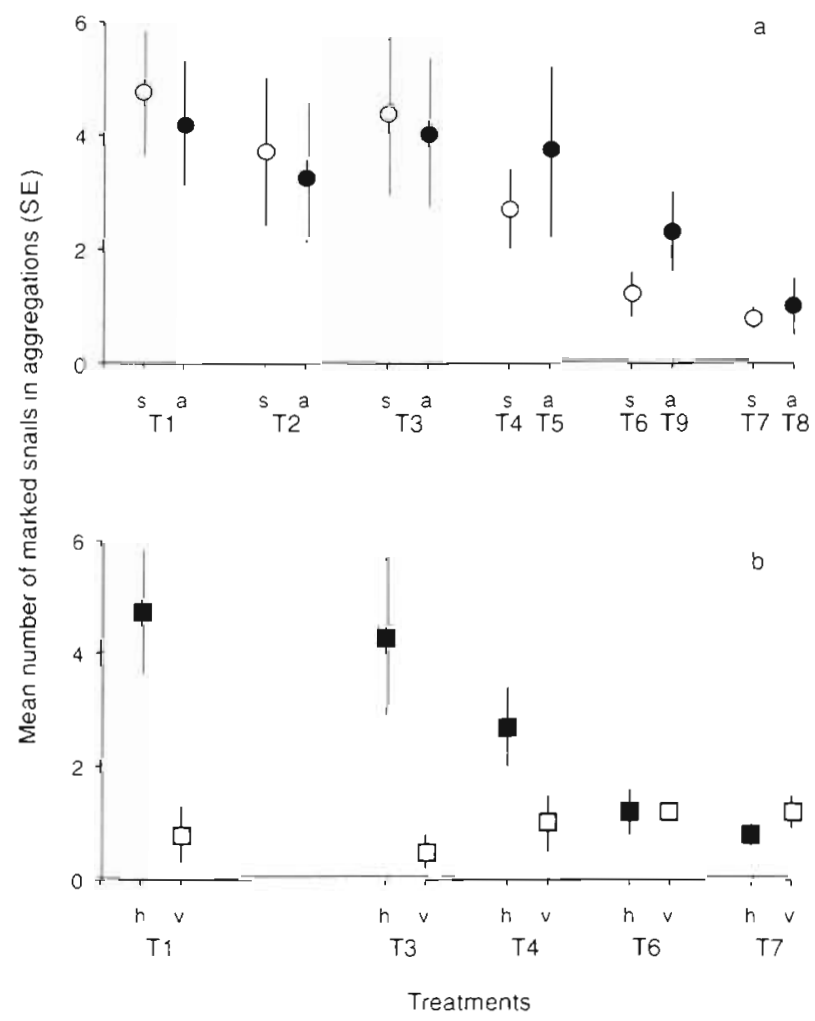

Fig. 4. Littorina unifasciata. Mean number (SE) of snails found in aggregations after being subjected to different experimental treatments. (a) Solitary (O) and aggregated (- L L unifasciata originally obtained from horizontal surfaces; (b) solitary $L$. unifasciata originally obtained from horizontal (D) or vertical

() rock-surfaces (treatments as in Table 1); $\mathrm{n}=6$ 
2 quadrats in Site 1, which gave a negative $(r=-0.64$, $23 \mathrm{df}, \mathrm{p}<0.01$ ) and a significant positive correlation $(\mathrm{r}=0.65,23 \mathrm{df}, \mathrm{p}<0.01)$. In general, therefore, there was no relationship between numbers of snails in patches of habitat during low compared to during high. tide at a wide range of spatial scales.

Differences in mean densities between low and high tide were analysed for quadrats of $500 \mathrm{~cm}^{2}$, whereas differences in the variance:mean ratio and Lloyd's index of crowding were examined for quadrats of 500 , 120 and $20 \mathrm{~cm}^{2}$. Examples of these analyses are given. in Table 3 and the significant sources of variation for all of these analyses are summarised in Table 4.

At a scale of $500 \mathrm{~cm}^{2}$, neither mean densities nor mean crowding varied between low and high tide (Tables 3 \& 4), indicating that densities of snails in patches of this size did not change between the 2 tidal conditions. Differences in mean densities between sites accounted for the significant differences in crowding between sites. In 2 quadrats, aggregation differed significantly between low tide and high tide (i.e. there was more variability among quadrats of this size; Table 3). but the pattern differed between quadrats. Snails were more patchy during low tide in one quadrat (i.e. there was greater variance:mean ratio) and more patchy during high tide in the other. In all other quadrats there were no significant differences.

At the smaller scale of $120 \mathrm{~cm}^{2}$, snails were more aggregated during low than during high tide (Table 4; after the Tide $\times$ Quadrat(Site) and Tide $\times$ Site interactions were pooled with the Residual), although snails were still aggregated during both stages of the tide as indicated by the variance: mean ration (low tide, mean $=7.36, \mathrm{SE}=$ 1.18; high tide, mean $=2.47, \mathrm{SE}=0.48$ ). The same trend was identified for Lloyd's index (Table 4; low tide, mean $=43.6, \mathrm{SE}=4.7$; high tide, mean $=35.37, \mathrm{SE}=3.5$ ).

Finally, at the smallest spatial scale of $20 \mathrm{~cm}^{2}$, there were similarly significant differences in aggregation and crowding between low and high tide in the different quadrats (Table 4). These were, however, only dif-

Table 3. Littorina unifasciata. Analyses of densities and aggregation (variance:mean ratio) among $500 \mathrm{~cm}^{2}$ subquadrats in $0.25 \mathrm{~m}^{2}$ quadrats in 2 sites at Cape Banks $(\mathrm{n}=2)$

\begin{tabular}{|c|c|c|c|c|c|}
\hline \multirow{2}{*}{$\begin{array}{l}\text { Source of } \\
\text { variation }\end{array}$} & \multirow[t]{2}{*}{$\mathrm{df}$} & \multicolumn{2}{|c|}{ Densities } & \multicolumn{2}{|c|}{ Aggregation } \\
\hline & & MS & F & $\mathrm{MS}$ & $F$ \\
\hline Tide $=\mathrm{T}$ & 1 & 780.1 & $0.72 \mathrm{~ns}$ & 1.3 & $1.27 \mathrm{~ns}$ \\
\hline Site $=S$ & 1 & 117128.0 & $40.97 \cdots$ & 66.8 & $0.69 \mathrm{~ns}$ \\
\hline$T \times S$ & 1 & 1081.1 & $0.83 \mathrm{~ns}$ & 1.0 & $0.01 \mathrm{~ns}$ \\
\hline Quadrat(S) & 6 & 2859.2 & $2.69 \mathrm{~ns}$ & 97.0 & 3.34 \\
\hline$T \times Q(S)$ & 6 & 1309.1 & $1.23 \mathrm{~ns}$ & 174.8 & $6.03 \cdots$ \\
\hline Residual & 16 & 1063.2 & & 29.1 & \\
\hline Cochran's test & & $C=0.17$ & $p>0.05$ & $C=0.1$ & $p>0.05$ \\
\hline
\end{tabular}

Table 4. Littorina unifasciata. Significant sources of variation in analyses of densities, aggregation (variance:mean ratio) and Lloyd's index of crowding among $500 \mathrm{~cm}^{2}$ subquadrats, and aggregation and Lloyd's index of crowding among $120 \mathrm{~cm}^{2}$ and $20 \mathrm{~cm}^{2}$ subquadrats, in $0.25 \mathrm{~m}^{2}$ quadrats at 2 sites at Cape Banks $(n=2)$. Tide is low compared to high tide

\begin{tabular}{|c|c|c|c|c|c|c|c|}
\hline \multirow[t]{2}{*}{$\begin{array}{l}\text { Sources of } \\
\text { variation }\end{array}$} & \multirow{2}{*}{$\begin{array}{l}\text { Densities } \\
\qquad \begin{array}{c}500 \\
\mathrm{~cm}^{2}\end{array}\end{array}$} & \multicolumn{3}{|c|}{ Variance:mean } & \multicolumn{3}{|c|}{$\begin{array}{l}\text { Lloyd's index } \\
\text { of crowding }\end{array}$} \\
\hline & & $\begin{array}{l}500 \\
\mathrm{~cm}^{2}\end{array}$ & $\begin{array}{l}120 \\
\mathrm{~cm}^{2}\end{array}$ & $\begin{array}{c}20 \\
\mathrm{~cm}^{2}\end{array}$ & $\begin{array}{l}500 \\
\mathrm{~cm}^{2}\end{array}$ & $\begin{array}{l}120 \\
\mathrm{~cm}^{2}\end{array}$ & $\begin{array}{r}20 \\
\mathrm{~cm}^{2}\end{array}$ \\
\hline Tide $=\mathrm{T}$ & ns & ns & $\mathrm{ns}^{\mathrm{a}}$ & ns & ns & $n 5^{b}$ & ns \\
\hline Site $=\mathrm{S}$ & $\cdots$ & ns & $\cdots$ & ns & $\cdots$ & ns & $\cdot$ \\
\hline $\mathrm{T} \times \mathrm{S}$ & ns & ns & ns & ns & ns & ns & ns \\
\hline Quadrat(S) & ns & & ns & $\cdots$ & 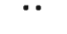 & $\cdots$ & ns \\
\hline$T \times Q(S)$ & ns & $\cdots$ & ns & $\cdots$ & ns & ns & • \\
\hline Cochran's test & ns & ns & ns & ns & $\mathrm{ns}$ & ns & ns \\
\hline \multicolumn{8}{|c|}{$\begin{array}{l}\text { "Pooling Residual, } \mathrm{T} \times \mathrm{Q}(\mathrm{S}) \text { and } \mathrm{T} \times \mathrm{S}(\mathrm{MS}=12.96) \text { : } \\
\text { test for Tide } F=14.84 ; 1 \text { and } 23 \mathrm{df}, \mathrm{p}<0.001\end{array}$} \\
\hline \multicolumn{8}{|c|}{$\begin{array}{l}\text { Pooling Residual, } T \times Q(S) \text { and } T \times S(M S=90.52) \text { : } \\
\text { test for Tide; } F=6.06 ; 1 \text { and } 23 \mathrm{df}, \mathrm{p}<0.05\end{array}$} \\
\hline
\end{tabular}

ferences in extent and in all quadrats snails were more aggregated and therefore subjected to more crowding during low than during high tide (Fig. 5).
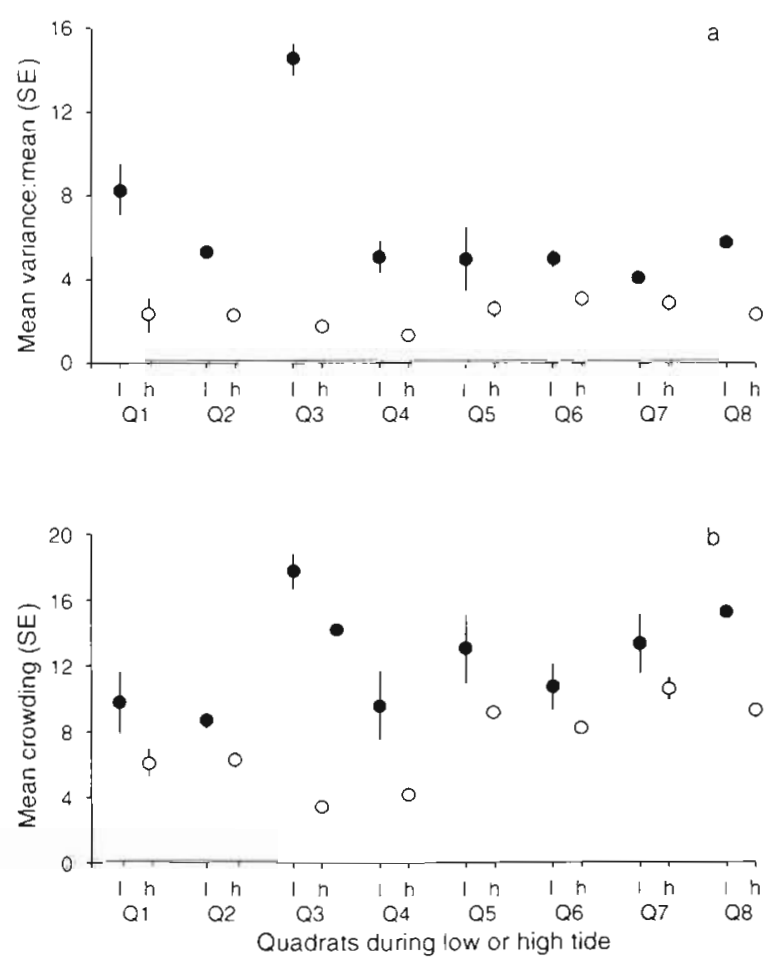

Fig. 5. Littorina unifasciata. (a) Variance:mean ratio and (b) Lloyd's index of crowding among $20 \mathrm{~cm}^{2}$ subquadrats between 2 subquadrats in each of eight $0.25 \mathrm{~m}^{2}$ quadrats ( $Q 1$ to Q4 in Site 1; Q5 to Q8 in Site 2) during low tide ( $\bullet$ ) or high tide (o) $(n=2)$ 


\section{DISCUSSION}

This study showed that Littorina unifasciata were frequently, but not invariably, significantly aggregated while emersed during low tide, during which time the snails were inactive. Aggregation varied spatially and was not correlated with either the density of the snails or the topographic complexity of the rock surface. It was, however, significantly greater at higher than at lower levels on the more wave exposed-shore, but showed the reverse pattern on the sheltered shore. Averaged over both heights, there was no difference between the 2 shores. Therefore aggregation in $L$. unifasciata cannot be correlated with factors previously cited as being important, such as density, complexity of habitat (Levings \& Garrity 1983, Garrity \& Levings 1984, Moran 1985), height on the shore and wave exposure (Chelazzi et al. 1984, Garrity \& Levings 1984). L. unifasciata generally showed as much difference in aggregation among sites a few metres apart as among sites at different heights on the shore, or among sites on different shores. This indicates that the variables that determine the degree of aggregation in this species operate at small spatial scales.

Littorina unifasciata do not home to particular sites (Chapman 1986, Underwood \& Chapman 1989), although they do consistently tend to move into particular patches of habitat after foraging (Underwood \& Chapman 1992). They do not necessarily return to the same patches each time and individuals gradually disperse from areas (Underwood \& Chapman 1989). Nevertheless, interchange of populations over large areas of the shore is unlikely (Chapman 1995). This study showed that the degree to which the snails aggregated in the same patches varied from time to time, suggesting that the cues which stimulate the snails to aggregate are not determined by invariant features of the habitat. Therefore, although there are patches of habitat in which densities of $L$. unifasciata are consistently greater during low tide, the degree to which the snails aggregate (or cluster) in these patches varies. The cues that stimulate aggregation are therefore likely to be more variable than those that cause snails to move towards or stay within patches of habitat.

Despite this variability, Littorina unifasciata on steep (vertical) slopes were significantly less aggregated than those on horizontal or shallow-sloping surfaces. In addition, aggregated snails were significantly smaller than solitary snails in one of the 2 study sites. Despite this significant pattern between size and aggregation. snails were not consistent in their tendency to aggregate on either steep or shallow slopes in this site. After a period of foraging, snails obtained from aggregations (smaller individuals) did not show a greater tendency to move into aggregations than did solitary snails (larger individuals). Species which return to aggregations via trail-following (e.g. Chelazzi et al. 1985) may indicate that snails found in aggregations are more responsive to trails of conspecifics than are solitary individuals. This is not likely to be true in L. unifasciata because there was no greater tendency for snails placed in an aggregation (irrespective of their origin) to return to an aggregation than was the case for originally solitary snails. Snails in all treatments showed less tendency to aggregate on vertical surfaces than on horizontal surfaces. This suggests that, on steeplysloping surfaces, the cues that stimulate aggregation (e.g. responses to desiccation or high temperatures; Garrity 1984) are less abundant, less strong or operate less consistently. The lack of correlation between aggregation and height on the shore and wave exposure, all of which are likely to differ in these physical conditions, indicates that other variables influence the responses of these snails.

Although the behaviour of individuals was not consistent from time to time, individuals obtained from steeply sloping surfaces were also less likely to aggregate than snails from horizontal surfaces, irrespective of the habitat into which they were transplanted. Because Littorina unifasciata found on vertical surfaces were generally larger and occured at lower densities than those on horizontal surfaces (see also Chapman 1994b), it is not possible to separate the effects of size, recent effects of conspecific density or other unknown factors on these differences in behaviour. These can only be differentiated with field experiments in areas in which snails of similar sizes and a range of densities can be found on both the vertical and horizontal surfaces. Such study sites have not been found.

Significantly, aggregation during low tide may not be a response to environmental conditions during emersion. Because Littorina unifasciata live at relatively high levels on the shore, they can become emersed and form aggregations between 2 and $4 \mathrm{~h}$ before the actual time of low tide. Therefore, the environmental conditions that exist at the time of low tide may be relatively unimportant cues for aggregation. For example, if low tide is at midday, when it can be extremely hot, the snails are likely to be emersed between 8:00 and 10:00 h when it is still relatively cool. In addition, $L$. unifasciata may aggregate before they are emersed, as do other species (Moulton 1962), in which case they may aggregate in response to cues present during high tide. Therefore dispersion of $L$. unifasciata was examined during low and high tide at a range of spatial scales from 20 to $2500 \mathrm{~cm}^{2}$

Littorina unifasciata showed different patterns of dispersion during low and high tide according to the spatial scale at which the populations were examined. 
Although densities were very variable from patch to patch, mean densities remained relatively constant at all scales in comparisons between low and high tide, indicating no large-scale movement of individuals into or out of the study sites. Within each study site, there were few significant relationships between the number of snails in a patch (between 20 and $2500 \mathrm{~cm}^{2}$ ) during low tide and the numbers in that patch during high tide. Therefore, in general, L. unifasciata do not aggregate in the same patches during high tide as during low tide. Neither do they move from a set of patches during low tide to a different set during high tide.

Littorina unifasciata were less aggregated during high tide in small patches of habitat (20 and $120 \mathrm{~cm}^{2}$ quadrats). The snails dispersed more evenly among patches while active and feeding, but aggregated into fewer patches when emersed. These patterns were not found in the larger patches (quadrats), indicating that the cues that stimulate aggregation should be identified at these small spatial scales. Differences in patterns of dispersion of $L$. unifasciata from place to place and time to time may therefore be explained by differences in grain or intensity of these smallscale, local cues to which the snails apparently respond.

These patterns are important for future studies of the effects of intraspecific density on aspects of the biology of Littorina unifasciata. Because the degree to which $L$. unifasciata aggregate differs between low and high tide, snails are subjected to changing effects of crowding within a single day. Individuals are less crowded during high tide (when they are feeding) than during low tide (when they are inactive). A study of the effects of increased density on their ecology (as should be the case for any species that aggregates) should include measurements of aggregation and crowding, in addition to the average density. These should be measured during the state of the tide relevant to the particular model being considered. If it is proposed that the snails are subjected to densitydependent effects during emersion (e.g because there are few sheltering sites), these variables should be measured during low tide when increased aggregation may increase effects of density. Alternatively, if it is proposed that the snails are affected by density of conspecifics during high tide (e.g. because of availability of food), the relevant variables should be measured during high tide. Measurements during low tide are likely to overestimate the effect of crowding on the snails and hence might enhance any perceived effect of crowding.

Therefore, patterns must be documented at a range of spatial scales. Clear models should be proposed to explain these patterns and experimental tests at the appropriate scales must be done before patterns of dispersion, such as those shown here, can be understood. Documentation of patterns is an essential first step in this understanding. It must include measures at several spatial scales and adequate replication to provide a convincing account of the patterns.

Acknowledgements. This research was supported by funds from the Institute of Marine Ecology and the School of Biological Sciences, University of Sydney, Australia. I thank T Crowe, S. J. Hawkins, A. J. Underwood and 2 anonymous referees for helpful comments on an earlier draft of this manuscript.

\section{LITERATURE CITED}

Bovjberg RV (1984) Habitat selection in two intertidal snails, genus Nerita. Bull mar Sci 34:185-196

Chapman MG (1986) Assessment of some controls in experimental transplants of intertidal gastropods. J exp mar Biol Ecol 103:181-201

Chapman MG (1992) Living at the fringe of intertidal society PhD thesis, University of Sydney

Chapman MG (1994a) Small- and broad-scale patterns of distribution of the upper-shore littorinid Nodilittorina pyramidalis in New South Wales. Aust J Ecol 19:83-95

Chapman MG (1994b) Small-scale patterns of distribution and size-structure of the intertidal littorinid, Littorina unifasciata (Gastropoda: Littorinidae) in New South Wales. Aust J mar Freshwat Res 45:635-652

Chapman MG (1995) Spatial patterns of shell shape in three species of co-existing littorinid snails in New South Wales, Australia. J mollusc Stud 61:141-162

Chapman MG. Underwood AJ (1992) Experimental designs for analyses of movements by molluscs. In: Grahame J, Mill PJ, Reid DG (eds) Proceedings of the Third International Symposium on Littorinid Biology. The Malacological Society of London, p 169-180

Chapman MG, Underwood AJ (1994) Dispersal of the intertidal snail, Nodilittorina pyramidalis, in response to the topographic complexity of the substratum. J exp mar Biol Ecol 179:145-169

Chelazzi G, Della Santina P, Vannini M (1985) Long-lastıng substrate marking in the collective homing of the gastropod Nerita textilis. Biol Bull mar biol Lab, Woods Hole 168: $214-221$

Chelazzi G, Lavoci G, Parpagnoli D (1988) Relative importance of arrborne odours and trails in group homing of Limacus flavus (Linnaeus) (Gastropoda, Pulmonata). J mollusc Stud 54:173-180

Chelazzi G, Vannini $M$ (1980) Zonal orientation based on local visual cues in Nerita plicata L. (Mollusca Gastropoda) at Aldabra Atoll. J exp mar Biol Ecol 46 $147-156$

Connell JH (1975) Some mechanusms producing structure in natural communities: a model and evidence from field experiments. In: Cody MS, Diamond JM (eds) Ecology and evolution of communities. Harvard University Press, Cambridge, MA, p 460-490

Cook SB (1971) A study of homing behaviour in the limpet Siphonaria alternata. Biol Bull 141:449-457

Cook SB, Cook CB (1975) Directionality in the trail-following response of the pulmonate limpet Siphonaria alternata. Mar Behav Physiol 3:147-155 
Dayton PK (1971) Competition, disturbance, and community organization: the provision and subsequent utilization of space in a rocky intertidal community. Ecol Monogr 41:351-389

Den Boer PJ (1968) Spreading of risk and stabilization of animal numbers. Acta Biotheor 18:165-194

Denley EJ, Underwood AJ (1979) Experiments on factors influencing settlement, survival and growth of two species of barnacles in New South Wales. J exp mar Biol Ecol 36: 269-293

De Wolf P (1973) Ecological observations on the mechanisms of dispersal on barnacle larvae during planktonic life and settling. Net.. J Sea Res 6:1-129

Evans F (1961) Responses to disturbance of the periwinkle Littorina punctata (Gmelin) on a shore in Ghana. Proc zool Soc Lond 137:393-402

Fairweather PG (1988) Movements of intertidal whelks (Morula marginalba and Thais orbita) in relation to availability of prey and shelter. Mar Biol 100:63-68

Feare CJ (1971) The adaptive significance of aggregation behaviour in the dog whelk, Nucella lapillus (L.). Oecologia $7: 117-126$

Garrity SD (1984) Some adaptations of gastropods to physical stress on a tropical rocky shore. Ecology 65:559-574

Garrity SD, Levings SC (1984) Aggregation in a tropical neritid. Veliger 27:1-6

Greig-Smith P (1952) The use of random and contiguous quadrats in the study of the structure of plant communities. Ann Bot 16:293-316

Hamilton PV (1978) Adaptive visually-mediated movements of Littorina irrcrata (Mollusca: Gastropoda) when displaced from their natural habitat. Mar Behav Physiol 5:255-271

Hawkins SJ, Hartnoll RG (1982) Settlement patterns of Semibalanus balanoides (L.) in the Isle of Man (1977-1981) $J$ exp mar Biol Ecol 62:271-283

Hill AS. Hawkins SJ (1991) Seasonal and spatial variation of epilithic microalgal distribution and abundance and its ingestion by Patella vulgata on a moderately exposed rocky shore. J mar biol Ass UK 71:403-423

Jenner CE (1959) Aggregation and schooling in the marine snail Nassarius obsoletus. Biol Bull mar biol Lab, Woods Hole 117:397

Keough MJ, Downes BJ (1982) Recruitment of marine invertebrates - the role of active larval choices and early mortality. Oecologia 54:348-352

Levings SC, Garrity SD (1983) Diel and tidal movement of two co-occurring neritid snails: differences in grazing patterns on a tropical rocky shore. J exp mar Biol Ecol 67:261-278

Lively CM, Raimondi PT (1987) Desiccation, predation, and mussel-barnacle interactions in the northern Gulf of California. Oecologia 74:304-309

Lloyd M (1967) Mean crowding. J Anim Ecol 36:1-30

Mackay DA, Underwood AJ (1977) Experimental studies on homing in the intertidal patellid limpet Cellana tramoserica (Sowerby). Oecologia 30:215-237

Marchetti KE, Geller JB (1987) The effect of aggregation and microhabitat on desiccation and body temperature of the black turban snail, Tegula funebralis (A. Adams, 1855). Veliger 30:127-133

Menge BA, Sutherland JP (1976) Species diversity gradients: synthesis of the roles of predation, competition and temporal heteroceneity. Am Nat 34:1-16

Moran MJ (1985) Distribution and dispersion of the predatory intertidal gastropod Morula marginalba Blainville. Mar Ecol Prog Ser 22:41-52

Moulton JS (1962) Intertidal clustering of an intertidal gastropod. Biol Bull mar biol Lab, Woods Hole 123:170-178
Paine RT, Levin SA (1981) Intertidal landscapes: disturbance and the dynamics of pa:tern. Ecol Monogr 51:14.5-178

Pielou EC (1959) The use of point-to-plant distances in the study of the pattern of piant populations. J Ecol 47:607-613

Pielou EC (1969) An introduction to mathematical ecology. John Wiley \& Sons, Inc, New York

Rhode K, Sandland R (1975) Factors influencing clustering in the intertidal snail Cerithium monoliferum. Mar Biol 30: $203-216$

Sousa WP (1984) Intertidal mosaics: patch size, propagule availability, and spatially variable patterns of succession Ecology 65:1918-1935

Southward AJ (1953) The ecology of some rocky shores in the south of the Isle of Man. Proc Liverpool biol Soc 59:1-50

Stanton ML (1983) Spatial patterns in the plant community and their effects upon insect search. In: Ahmad S (ed) Herbivorous insects. Host-seeking behaviour and mechanisms. Academic Press, New York, p 125-151

Turchin $P(1987)$ The role of aggregation in the response of Mexican bean beetles to host-plant density. Oecologia 71 $577-582$

Turchin P (1988) Models for aggregation populations. In: Hallam T G, Gross L J, Levin S A (eds) Mathematical ecology. World Scientific, Singapore, p 101-117

Underwood AJ (1976a) Analysis of patterns of dispersion of intertidal prosobranch gastropods in relation to macroalgae and rock pools. Oecologia 25:145-154

Underwood AJ (1976b) Nearest neighbour analysis of spatial dispersion of intertidal prosobranch gastropods within two substrata. Oecologia 26.257-266

Underwood AJ (1981a) Structure of a rocky intertidal community in New South Wales: patterns of vertical distribution and seasonal change. J exp mar Biol Ecol 51:57-85

Underwood AJ (1981 b) Techniques of analysis of variance in experimental marine b:ology and ecology. A Rev Oceanogr mar Biol 19:513-603

Underwood AJ (1988) Design and analysis of field experiments on competitive interactions affecting behaviour of intertidal animals. In: Chelazzi $G$, Vannini M (eds) Behavioural adaptation to intertidal life. NATO ASI Series A, Life Sciences, Vol :51. Plenum Press, New York, $p$ $333-357$

Underwood AJ, Chapman MG (1989) Experimental analyses of the influences of topography of the substratum on movements and density of an intertidal snail, Littorina unifasciata. J exp mar Biol Ecol 134:175-196

Underwood AJ, Chapman MG (1992) Experiments on topographic influences on density and dispersion of Littorina unifasciata in New South Wales. In: Grahame J, Mill PJ, Reid DG (eds) Proceedings of the Third International Symposium on Littorinid Biology. The Malacological Society of London, London, p 181-195

Underwood AJ, Denley EJ (1984) Paradigms, explanations and generalizations in models for the structure of intertidal communities on rocky shores. In: Strong DR, Simberloff D, Abele LG, Thistle A (eds) Ecological communities: conceptual issues and the evidence. Princeton University Press, Princeton, NJ, p 151-180

Underwood AJ, Jernakoff $\mathrm{P}$ (1984) The effects of tidal height, wave exposure, seasonality and rock pools on grazing and the distribution of intertidal macroalgae in New South Wales. J exp mar Biol Ecol 75:71-96

Wiens JA (1976) Population responses to patchy environments. A Rev Ecol Syst 7:81-120

Winer BJ (1971) Statistical principles in experimental design, 2nd edn. McGraw-Hill Kogakusha, Tokyo 